\title{
CONCEPÇÃO DE PROFESSORES DE EDUCAÇÃO FÍSICA EM RELAÇÃO À QUALIFICAÇÃO E ATUAÇÃO JUNTO DE ALUNOS COM DEFICIÊNCIA
}

\author{
Jessica Aline Schmitt, Universidade Estadual do Oeste do Paraná - UNIOESTE, Paraná - \\ Brasil \\ Robson Frank, Universidade Estadual do Oeste do Paraná - UNIOESTE, Paraná - Brasil \\ Douglas Roberto Borella, Universidade Estadual do Oeste do Paraná - UNIOESTE, Paraná - \\ Brasil \\ Angela Schone, Universidade Estadual do Oeste do Paraná - UNIOESTE, Paraná - Brasil \\ Anne Caroline Duarte, Universidade Federal de São Carlos - UFSCAR, São Carlos, São Paulo \\ - Brasil \\ Gabriela Simone Harnisch, Universidade Estadual de Campinas - UNICAMP, Campinas, São \\ Paulo - Brasil \\ Jalusa Andréia Storch, Universidade Estadual de Campinas - UNICAMP, Campinas, São \\ Paulo - Brasil
}

\section{RESUMO}

O presente estudo tem como objetivo averiguar a qualificação e dificuldades dos professores em relação ao trabalho diante de alunos com deficiência no contexto inclusivo ou na Modalidade de Educação Especial. Este estudo caracteriza-se como uma pesquisa de campo e exploratória, de cunho quantitativo. Os participantes do referido estudo foram 30 professores de Educação Física, já formados, atuantes em escolas e colégios da rede pública e privada. Para a coleta de dados utilizou-se de um (1) questionário, composto de questões fechadas, elaborado pelos pesquisadores. Os resultados apresentam que uma pequena parcela considera que a disciplina foi suficiente para atuar com esta população. As principais dificuldades na regência dos professores está em "proporcionar práticas pedagógicas adequadas" e em "conhecer as características da deficiência". Percebe-se que os professores reconheceram a importância que a atualização tem para essa área, porém, relatam não se interessar em fazer uma especialização. Contudo, observa-se que os professores não estão aptos para atuar com alunos com deficiência e apontam, principalmente, que, a falta de atualização nesta área dificulta o desenvolvimento de práticas pedagógicas inclusivas que garantam o desenvolvimento das potencialidades dos alunos e inclusive ensino de qualidade a pessoas com deficiência.

Palavras-Chave: Qualificação profissional; Professores; Pessoas com deficiência.

\section{DISEÑO DE PROFESORES DE EDUCACIÓN FÍSICA EN RELACIÓN CON LA CUALIFICACIÓN Y EXPERIENCIA CON LOS ESTUDIANTES CON DISCAPACIDADES}

\footnotetext{
RESUMEN

este estudio pretende determinar la calificación y las dificultades de los docentes en relación al trabajo frente a los estudiantes con discapacidades en contexto inclusivo o en educación especial. Este estudio se caracteriza como una investigación de campo y exploración de la naturaleza cuantitativa. Los participantes de este estudio estaba Conexões: revista da Faculdade de Educação Física da UNICAMP, Campinas, v. 13, n. 1, p. 1-19, jan./mar. 2015. ISSN: 1983-9030
} 
compuesta por 30 profesores de educación física, los alumnos, trabajando en escuelas y colegios públicos y privados. Datos de colección usa 1 un cuestionario, compuesto de preguntas cerradas, preparados por los investigadores. Los resultados muestran que una pequeña porción cree que la disciplina era suficiente para trabajar con esta población. Las principales dificultades en la realización de los profesores están en "proporcionando adecuadas prácticas pedagógicas" y en "cumplan con las características de la discapacidad". Se observa que los profesores reconocieron la importancia de actualizar a esta zona, no obstante, informe de no estar interesado en hacer una especialización. Sin embargo, se observa que los profesores no son capaces de trabajar con estudiantes con discapacidades y punto, principalmente, la falta de actualización en esta área hace que sea difícil proporcionar prácticas educativas inclusivas que garanticen el desarrollo de una educación de calidad inclusiva y potenciales estudiantes para personas con discapacidad.

Palabras-Clave: Cualificación profesional; Profesores; Personas con discapacidad.

\title{
CONCEPTION OF TEACHERS OF PHYSICAL EDUCATION IN RELATION TO QUALIFICATION AND ACTION TOGETHER FOR STUDENTS WITH DISABILITIES
}

\begin{abstract}
The present study aims to investigate the skills and difficulties of teachers in relation to work on students with disabilities in an inclusive context or mode of Special Education. This study is characterized as a quantitative research. The participants of the study consisted of 30 physical education teachers, already formed, working in schools and colleges, both public and private. For data collection we use done (1) questionnaire with closed questions, developed by the researchers. The results show that a small percentage believes that the discipline was enough to work with this population. The main difficulties in governing the teachers is to "provide appropriate pedagogical practices" and "to know the characteristics of the disability." It can be seen then that teachers recognize the importance that the update for this area, however, report no interest in doing a specialization. However, it is observed that the teachers are notable to work with students with disabilities and aim mainly to lack of updating this area makes it difficult to provide inclusive educational practices that ensure the development of the potential of students and inclusive quality education for people with disabilities.
\end{abstract}

Key-Words: Credentialing; Teachers; Disabled persons. 


\section{INTRODUÇÃO}

As ações, soluções, iniciativas e as inovações desempenhadas pelos professores no contexto escolar estão sempre embasadas em concepções e experiências que se tem sobre determinado assunto. Essas concepções são frutos de uma herança cultural e do processo de formação profissional, as quais são desenvolvidas dentro de uma conjuntura histórica pautadas por diferentes crenças e valores individuais.

Mendes ${ }^{1}$ definiu o termo concepção como um conjunto de informações que habilitam indivíduos, grupos sociais, a sociedade, ou a cultura, a: descrever as características do fenômeno ou a forma como ele se manifesta; identificar o fenômeno com base nas características descritas; explicar sua ocorrência através do estabelecimento de relações entre eventos determinados e consequentes; derivar estratégias para intervir na condição. Portanto, as concepções envolvem "um repertório ou conjunto de conhecimentos adquiridos no decorrer da história de vida das pessoas". 1:6

Quando tratamos do processo de inclusão de alunos com deficiência, a priori delineado neste estudo - nas aulas de Educação Física, a concepção que professores apresentam a respeito do conceito de deficiência parece estar vinculado à questão da formação profissional, envolvendo o conjunto de conhecimentos adquiridos desde a formação inicial até a continuada.

Monteiro $^{2}$ fundamenta o pensamento supracitado destacando que, a partir das experiências vividas, das informações recebidas e compartilhadas com os grupos sociais a qual o indivíduo pertence, da cultura em que estão inseridos, bem como da linguagem utilizada, os professores constroem concepções de forma processual e dinâmica.

Desta forma, as ações desenvolvidas no processo de ensino-aprendizagem escolar têm como base as concepções geridas dentro de um processo de construção do conhecimento, as quais posteriormente determinam atitudes e direcionam para a prática. Portanto, a inclusão de alunos com deficiência nas aulas de Educação Física pode estar pautado na construção dos saberes adquiridos pelos professores ao longo da formação inicial e continuada.

Conexões: revista da Faculdade de Educação Física da UNICAMP, Campinas, v. 13, n. 1, p. 1-19, jan./mar. 2015. ISSN: $1983-9030$ 
Alguns pesquisadores realizaram estudos sobre a formação profissional e concepção apresentada por professores de Educação Física junto à atuação de alunos com deficiência, dentre eles: Medina, ${ }^{3}$ Costa $^{4}{ }^{\text {Carmo, }}{ }^{5}$ Moreira $^{6}$ e Daólio. ${ }^{7}$ De modo geral, averiguou-se que a formação profissional desenvolveu-se com ênfase na formação esportivista ligada ao rendimento máximo do praticante, na seleção natural dos mais habilidosos e, acima de tudo, no entendimento de que os profissionais formavam-se na perspectiva do saber fazer para ensinar.

Analisando estes estudos, pode-se verificar que houve uma tentativa de fuga a este modelo préconcebido, sendo que, a partir da década de 80, algumas instituições de ensino superior implementaram novas propostas curriculares procurando formar o aluno numa perspectiva global, não supervalorizando o aspecto físico, como também as capacidades cognitivas, psicológicas e sociais. ${ }^{8}$ Baseado nesta perspectiva, os estudos relacionados às pessoas com deficiência também foram ampliados gradativamente e como consequência acarretaram novas áreas do saber acadêmico e profissional, implicando na delimitação da população alvo, nas terminologias atribuídas, nas diferentes metodologias de ensino, no desenvolvimento de testes e equipamentos específicos que visam avaliar a pessoa com deficiência nas diferentes capacidades corporais, para a vida diária, no ensino, no desporto, lazer e recreação. ${ }^{9-10}$

A Educação Física na escola constitui-se como uma oportunidade para a inclusão de crianças e jovens com deficiência, por meio de práticas de atividades físicas adaptadas ou especialmente elaboradas que vão de encontro com suas possibilidades e potencialidades, as quais visam desenvolver a corporeidade, autoimagem, autoestima e socialização. ${ }^{11}$

Neste cenário, o professor da Educação Física torna-se coadjuvante no processo de ensino e deve apresentar alguns conhecimentos que auxiliem na identificação das diferentes nuances apresentadas por seus alunos, tais como: tipo de deficiência, idade em que apareceu a deficiência, se foi repentina ou gradativa, se é transitória ou permanente, as funções e estruturas que estão prejudicadas. Implica, também, que esse educador conheça os diferentes aspectos do desenvolvimento humano: biológico (físicos, sensoriais, neurológicos); cognitivo; motor; interação social e afetivo-emocional. ${ }^{11}$

Atitudes positivas de professores em relação ao ensino de alunos com deficiência são necessárias para o sucesso de qualquer programa onde estes sejam participantes. $\mathrm{O}$ 
professor de Educação Física é o principal facilitador no processo ensino-aprendizagem de habilidades motoras e esportivas de alunos com e sem deficiência em diferentes ambientes. Enquanto ensina, o professor também transmite valores, normas, maneiras de pensar e padrões de comportamento, para se viver em sociedade. ${ }^{12}$

Para o professor que vai atuar com os alunos com deficiência, é fundamental que tenha conhecimento dos estudos sobre desenvolvimento e aprendizagem destes alunos, saiba elaborar e desenvolver um currículo apropriado às suas necessidades pessoais e sociais, tenha competência para selecionar, elaborar e usar materiais e equipamentos apropriados, saiba compreender o aluno em seu desenvolvimento individual e em suas relações familiares e sociais, tenha competência para trabalhar em equipe multidisciplinar. ${ }^{13}$

Para colaborar com o que Mazzotta já mencionava em 1997, Borella ${ }^{14}$ afirma que o bom profissional de Educação Física não é aquele que pratica e sabe executar determinada tarefa motora, mas aquele que compreende as necessidades do aluno e respeita as suas limitações, porque seu conhecimento permite perceber seu nível de aprendizagem e suas capacidades e, além disso, é capaz de despertar nas pessoas a consciência de que a atividade física é efetiva para proporcionar um nível de excelência em sua qualidade de vida.

A Educação Física deve contribuir na tarefa de garantir a educação escolarizada de todo e qualquer aluno. Além da complexidade inerente a articulação entre temas como alunos com deficiência, inclusão escolar e Educação Física, é necessário tratar com profundidade questões decorrentes da referida articulação. ${ }^{15}$

Daólio (apud Silva, Seabra Junior e Araújo), ${ }^{16}$ defende uma Educação Física que, no âmbito escolar, deveria atender a todos os alunos, considerando e respeitando suas diferenças.

Pelo exposto, sabe-se da importância que o professor de Educação Física exerce sobre o desenvolvimento motor, afetivo-social, cognitivo dos alunos, o qual pode-se tornar um agente potencial a favor da inclusão de alunos com deficiência e neste olhar o presente estudo visa responder a seguinte pergunta: qual é o nível de formação dos professores de Educação Física

Conexões: revista da Faculdade de Educação Física da UNICAMP, Campinas, v. 13, n. 1, p. 1-19, jan./mar. 2015. ISSN: 1983-9030 
que atuam com alunos com deficiência? Qual é a concepção em relação ao trabalho diante do contexto inclusivo ou na modalidade de Educação Especial?

\subsection{Objetivo}

Averiguar a qualificação e dificuldades dos professores em relação ao trabalho diante de alunos com deficiência no contexto inclusivo ou na Modalidade de Educação Especial.

\section{MÉTODOS}

2.1 Caracterização da pesquisa

Este estudo caracteriza-se como uma pesquisa de campo e exploratória, de cunho quantitativo, segundo os pressupostos de Thomas, Nelson e Silverman. ${ }^{17}$

\subsection{Participantes}

A amostra do referido estudo foi delimitada de forma não probabilística e aleatória, compreendendo 30 professores de Educação Física, já formados, atuantes em escolas e colégios da rede pública e privada.

\subsection{Instrumento para coleta de dados}

O instrumento utilizado para a coleta de dados constituiu-se de um (1) questionário, composto de questões fechadas, elaborado pelos pesquisadores. As questões englobaram perguntas relacionadas às disciplinas na matriz curricular que envolve pessoas com deficiência durante a formação inicial; as concepções em relação às dificuldades para conduzir as aulas de Educação Física em turmas que apresentem alunos com deficiência; a formação continuada destes professores.

Para adequação do instrumento, foram realizados três pilotos com uma população semelhante e não participante do estudo.

\subsection{Procedimentos para coleta de dados}

A presente pesquisa compreendeu fases distintas para o processo de coleta e discussão dos dados, sendo elas:

-1 $1^{\text {a }}$ etapa: Selecionaram-se os professores de Educação Física atuantes em escolas da rede pública e privada do município de Marechal Cândido Rondon;

Conexões: revista da Faculdade de Educação Física da UNICAMP, Campinas, v. 13, n. 1, p. 1-19, jan./mar. 2015. ISSN: 1983-9030 
- $2^{\text {a }}$ etapa: Contatou-se esses professores e relatou-se os objetivos da pesquisa através da carta de apresentação do estudo para verificar o interesse da participação;

-3 $3^{\text {a }}$ etapa: Após o convite e explanação de como se desenvolverá a pesquisa e consentimento dos participantes mediante a assinatura do termo de consentimento livre e esclarecido (TCLE) foi agendada data e local para a aplicação do questionário. Devese ressaltar que as entrevistas aconteceram individualmente no momento da realização da mesma e estavam no local apenas a pesquisadora e o participante do estudo, vale destacar que é o entrevistado que escolheu o lugar e as datas em que transcorreram os encontros.

\subsection{Análise dos dados}

Como este estudo caracterizou-se como uma pesquisa quantitativa, de tratamento estatístico descritivo, os dados tabulados e analisados em frequências relativas e absolutas, posteriormente apresentados por meio de gráficos utilizando-se do Microsoft Excel®, versão 2010.

\section{APRESENTAÇÃO E DISCUSSÃO DOS RESULTADOS}

Tendo em vista a importância do conhecimento, de cunho teórico e prático, voltado a pessoas com deficiência, apresentar-se-á os resultados referentes à disciplina que contempla tal conteúdo nos cursos de graduação, explanando-se as dificuldades dos professores em conduzir suas intervenções, bem como a formação complementar dos docentes que atuam com essa população:

\subsection{Quanto à disciplina na matriz curricular que envolve pessoas com deficiência na graduação}

Em relação ao questionamento que verificou se esta disciplina/conteúdo, na graduação, foi suficiente para prepará-los para atuar junto a pessoas com deficiência, apresenta-se a Figura 1. 


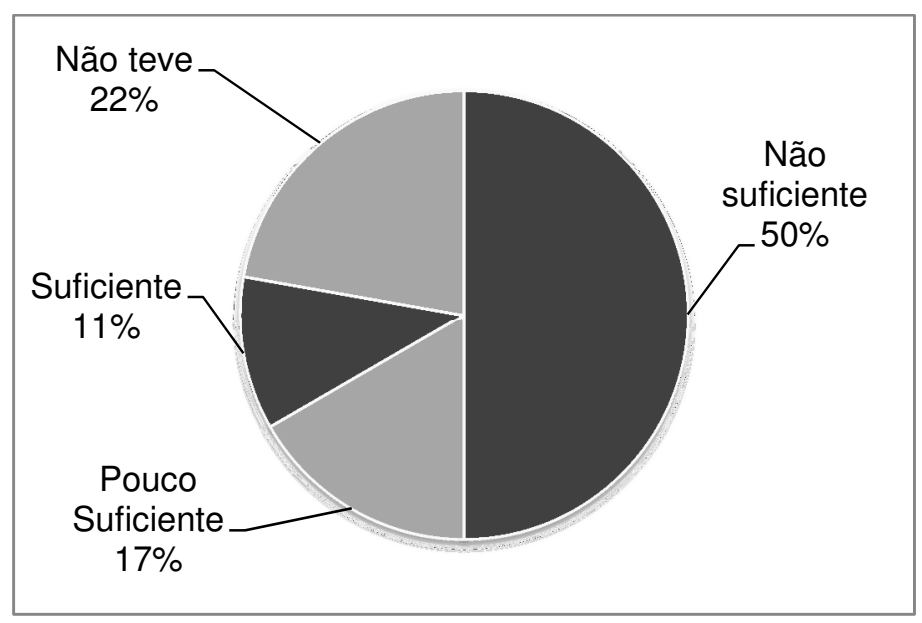

Figura 1: Preparação na graduação pela(s) disciplina(s).

Por meio da Figura 1, observa-se que 50\% dos professores afirmaram que somente esta disciplina/conteúdo "Não foi suficiente" e 17\% relataram ser "Pouco suficiente", e somente $11 \%$ consideraram a mesma como "Suficiente". Ainda, 22\% expuseram que não tiveram nenhuma disciplina com a temática envolvendo pessoas com deficiência, de maneira específica. Vale destacar que apenas $78 \%$ da amostra que compôs o presente estudo, respondeu a esta questão.

Neste ínterim, ressalta-se que, os conhecimentos relacionados a pessoas com deficiência começaram a ser difundidos oficialmente nos cursos de graduação por meio da Resolução 3/87 do Conselho Federal de Educação, que prevê a atuação do professor de Educação Física com pessoas com deficiência e outros grupos especiais. Por isso, muitos docentes atuantes no ambiente escolar não foram contemplados, no curso de graduação, com conteúdos e/ou assuntos pertinentes a estas populações. ${ }^{11,18}$

Desta forma, por meio da Figura 1, é possível verificar que a maioria dos professores sentem-se insuficientemente preparados para o trabalho envolvendo pessoas com deficiência. Uma das hipóteses estabelecidas para tais respostas é que os professores afirmaram que, $22 \%$ não tiveram uma disciplina específica, e dentre os que cursaram, apenas $11 \%$ relataram sentir-se preparados para suas atuações docentes frente a estes alunos. Ainda, destaca-se que, a amostra do estudo foi constituída de professores com idade superior a 30 anos, e nem todos estes tiveram a oportunidade de frequentar, durante a graduação, uma disciplina específica.

Conexões: revista da Faculdade de Educação Física da UNICAMP, Campinas, v. 13, n. 1, p. 1-19, jan./mar. 2015. ISSN: 1983-9030 
Neste sentido, explana-se a importância da qualificação profissional, por meio de cursos de pós-graduação, e outros que possam influenciar positivamente nas intervenções docentes junto a alunos com deficiência em aulas de Educação Física, de modo que, a Educação Física ainda encontra-se respaldada em alguns preconceitos. Estes acontecimentos têm raízes na origem da Educação Física no Brasil e seus reflexos nos cursos de formação profissional da época de formação dos professores que responderam ao questionamento, cuja formação estava ligada diretamente ao âmbito esportivo e não ao processo de escolarização.

Souza Neto et. al., ${ }^{19}$ corroboram que o primeiro curso de Educação Física que se tem notícia foi criado em 1931, em São Paulo, mas só iniciou em 1934. Neste, o tempo de duração era de dois anos e sua formação se fundamentava, apesar do compromisso definido como de um educador, no desenvolvimento de habilidades de um técnico desportista. O outro, com duração de um ano, tinha como objetivo a formação de instrutores de ginástica para desenvolver nas aulas o estudo da vida humana em seus aspectos celular, anatômico, funcional, mecânico, preventivo.

Observa-se que a formação do profissional de Educação Física estava sendo desenvolvida de maneira acrítica, que existia uma ênfase na formação esportivista ligada ao rendimento e seleção dos mais habilidosos, e que os profissionais eram formados na perspectiva do saber fazer para ensinar. ${ }^{14}$

Desta forma, entende-se que, principalmente, professores que concluíram seus cursos de graduação em Educação Física antes da inserção de leis que tornam obrigatório os conteúdos envolvendo pessoas com deficiência, necessitam de cursos de qualificação, bem como, de buscar metodologias e estratégias de ensino para que os conteúdos a serem repassados no ambiente escolar contemplem, também, a alunos com deficiência.

\subsection{Principais dificuldades dos professores em conduzir aulas com alunos com deficiência}

Quando os professores foram questionados sobre as principais dificuldades em conduzir aulas em turmas que contemplem alunos com deficiência, elucida-se a Figura 2.

Conexões: revista da Faculdade de Educação Física da UNICAMP, Campinas, v. 13, n. 1, p. 1-19, jan./mar. 2015. ISSN: 1983-9030 


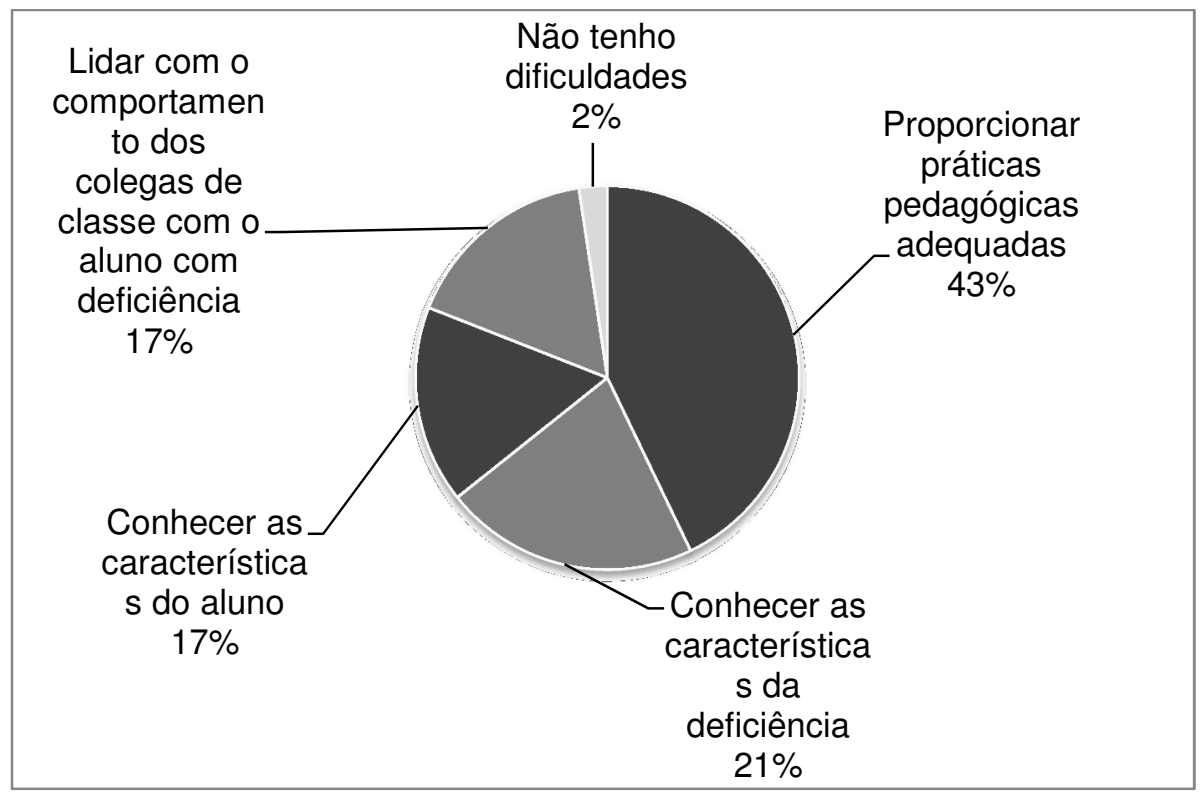

Figura 2: Dificuldades em conduzir aulas com alunos com deficiência.

Verifica-se na Figura 2 que a principal dificuldade dos professores em conduzir aulas com alunos com deficiência está em "proporcionar práticas pedagógicas adequadas" (43\%). Outra opção mencionada foi a de "conhecer as características da deficiência" (21\%). Já em relação a "conhecer as características do aluno" e "saber lidar com o comportamento dos demais colegas de classe", estes tiveram a mesma porcentagem $(17 \%)$, e apenas $2 \%$ dos professores assinalaram a opção de "não tenho dificuldades".

A fim de averiguar se os professores acreditam que é necessário conhecer a origem/causas da deficiência do aluno para estar habilitado a desenvolver seu trabalho, expôs-se somente duas opções: "Sim" e "Não", na qual o resultado apontou que 95\% dos professores acreditam ser necessário e apenas 5\% apontaram que não é necessário conhecer a origem/causa da deficiência.

Posteriormente a esta abordagem, solicitou-se que os professores justificassem esta resposta. Desta forma, 69\% relataram que irá depender da deficiência e 31\% apontaram que conhecendo a deficiência é possível realizar um melhor trabalho para com estes alunos.

Conexões: revista da Faculdade de Educação Física da UNICAMP, Campinas, v. 13, n. 1, p. 1-19, jan./mar. 2015. ISSN: 1983-9030 
Os dados demonstram semelhanças com estudo desenvolvido por Filus e Martins Junior, ${ }^{20}$ na medida que, $78,57 \%$ dos professores participantes da pesquisa sentiram dificuldades no início da carreira, principalmente pela falta de experiência em suas atividades docentes envolvendo pessoas com deficiência, alegando ausência de informação e conhecimento sobre características das deficiências durante a graduação, além de conhecerem poucos profissionais que possibilitem a troca de experiência.

No entanto, além de conhecimentos em relação aos alunos, Maciel $^{21}$ comenta que há a necessidade de integração entre professor e aluno. Para tanto, o professor do ensino regular e os especialistas de educação das escolas precisam ter conhecimento sobre o que é deficiência, quais são seus principais tipos, causas, características e as necessidades educativas de cada uma delas. O educador precisa, antes de tudo, ter ampla visão desta área, que deve ser proveniente de sua formação acadêmica. Poucas Instituições de Ensino Superior, que formam professores, abordam adequadamente a questão da deficiência em seus currículos. A atualização periódica também é indispensável, devendo ocorrer por meio de cursos, seminários e formação em serviço.

É importante que os professores tomem ciência do diagnóstico e do prognóstico do aluno com deficiência. Neste sentido, sugere-se que os docentes envolvidos no processo de ensino e aprendizagem conversem com pais ou responsáveis para conhecer todo o histórico de vida do mesmo, a fim de traçar estratégias conjuntas; peçam orientações e procurem profissionais como psicólogos, fisioterapeutas, fonoaudiólogos que estejam atendendo ou que já atenderam tal aluno; realizem pesquisas que envolvam métodos e estratégias de ensino, em que variáveis como o desenvolvimento da linguagem, o desenvolvimento físico e, sobretudo, as experiências sociais estejam presentes. ${ }^{21}$

Deste modo, acredita-se que os professores devem conhecer seus alunos, de modo que cada um possui suas características e peculiaridades, em virtude de que a diversidade humana contempla uma ampla gama de diferenças entre cada pessoa, seja ela com ou sem deficiência. 


\subsection{Formação continuada e complementar dos professores}

Sobre ter ou não condições de atuar com pessoas com deficiência, sem precisar buscar curso de atualização/especialização, a Figura 3 aponta as respostas relatadas pelos professores.

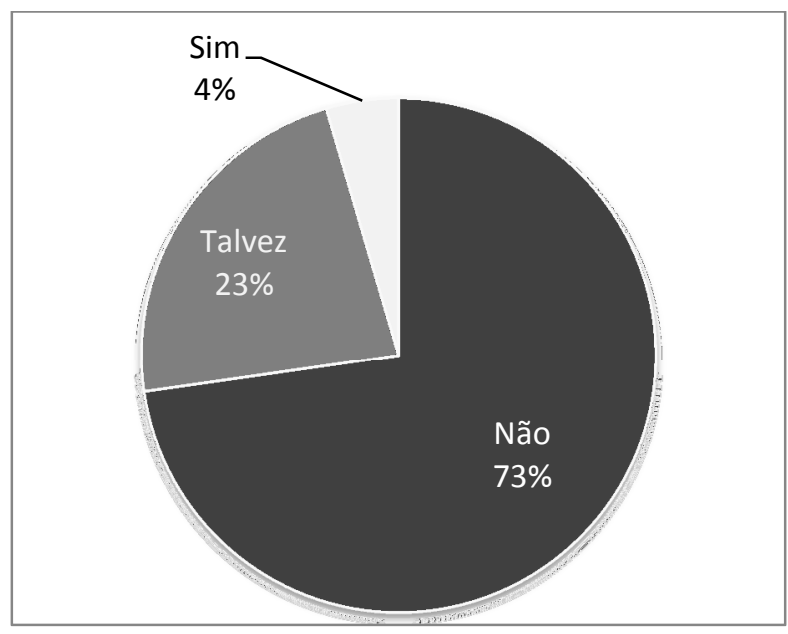

Figura 3: Condições de atuar com pessoas com deficiência sem curso de atualização/especialização.

Quanto aos professores envolvidos neste estudo, 73\% afirmam que "não possuem condições de atuar sem cursolespecialização". Já 23\% assinalaram que "Talvez" tenham condições e somente $4 \%$ afirmam "ter condições de atuar sem cursolespecialização”.

Filus e Martins Junior, ${ }^{20}$ em seu estudo, demonstraram de maneira similar que poucos dos professores pesquisados $(21,42 \%)$ consideraram que a sua formação lhes forneceu subsídios suficientes para trabalhar e ministrar as aulas, embora tenham enfatizado que não se pode parar de estudar. Muitos dos profissionais consultados $(78,58 \%)$ não se sentiram confiantes em trabalhar com pessoas com deficiência logo ao sair da graduação.

Por meio dos dados apresentados por ambas as pesquisas, é notório que muitos professores não sentem-se em condições de atuar com esta população alegando fatores que refletem principalmente na formação acadêmica oriunda da graduação. Porém, não pode-se deixar de mencionar que a busca do conhecimento, na maioria das vezes, 
depende do interesse do próprio professor, em se atualizar para que seja possível proporcionar o conteúdo a todo o alunado.

Para justificar as opções assinaladas na Figura 3, apresentar-se-á a Figura 4, na qual são explanadas sugestões para que os professores tenham melhores condições em atuar junto a alunos com deficiência.

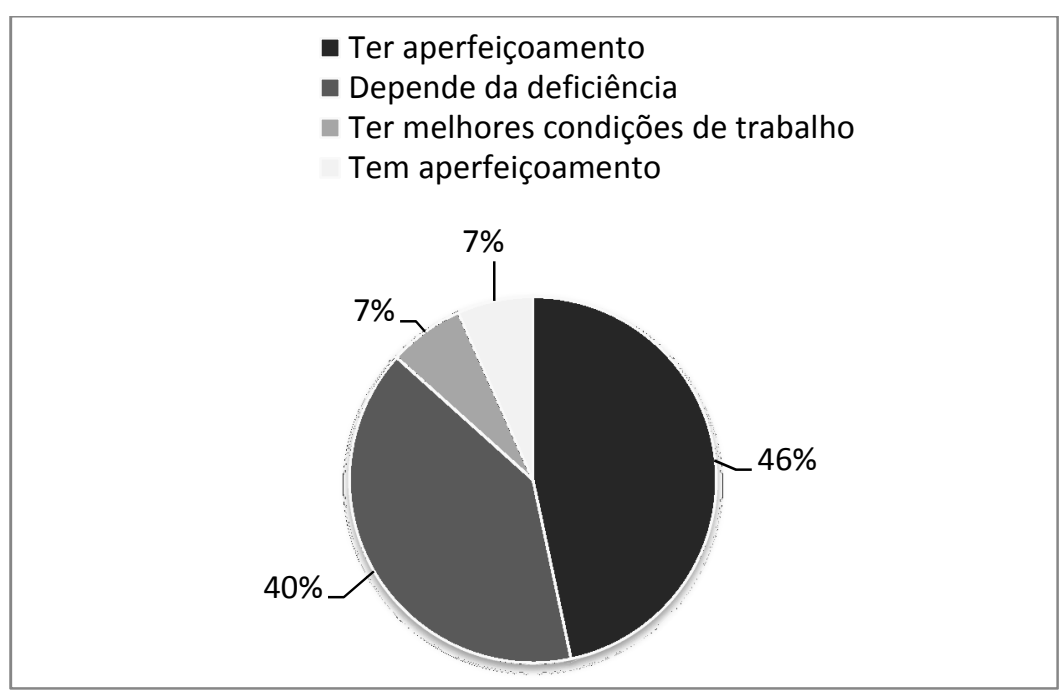

Figura 4: Motivos de não ter ou não condições de atuar junto a alunos com deficiência.

Por meio da Figura 4, é possível averiguar que $46 \%$ da amostra relatou a necessidade de “ter aperfeiçoamento", seguida por $40 \%$ que afirmaram que "depende da deficiência”, e "ter melhores condições de trabalho" apresentou-se em 7\% das respostas. Já os outros 7\%, afirmaram na Figura 3 que tem condições de atuar, em virtude de possuírem qualificação.

Assim, por meio da Figura 4, percebe-se que os docentes ainda precisam de aperfeiçoamento para atuar junto a alunos com deficiência. Portanto, é dever do professor buscar este aperfeiçoamento seja por ele próprio ou por meio de cursos da área.

O estudo realizado por Sant' Ana $^{22}$ também evidenciou a falta de qualificação dos professores e da equipe pedagógica em lidar com alunos com deficiência. Os docentes 
demonstraram entender que a habilitação específica deve ser o primeiro passo do processo inclusivo.

Seguindo este pensar, os participantes da pesquisa foram perguntados se possuem curso de especialização na área da Educação Especial ou Atividade Física Adaptada, a fim de averiguar se estes profissionais estão em busca de aperfeiçoamento e quantos se interessam nesta área.

Neste sentido, comprovou-se que $77 \%$ dos professores não possuem especialização nesta área e que somente $23 \%$ têm especialização sobre este tema. Este dado reflete que os professores precisam ter consciência de que a realização de cursos de especialização é importante para subsidiar suas atuações docentes.

Para averiguar o interesse dos mesmos nestes cursos, questionaram os professores que não possuem cursos de atualização sobre tal temática sobre o interesse em realiza-lo. Para elucidar os dados coletados, apresenta-se a Figura 5.

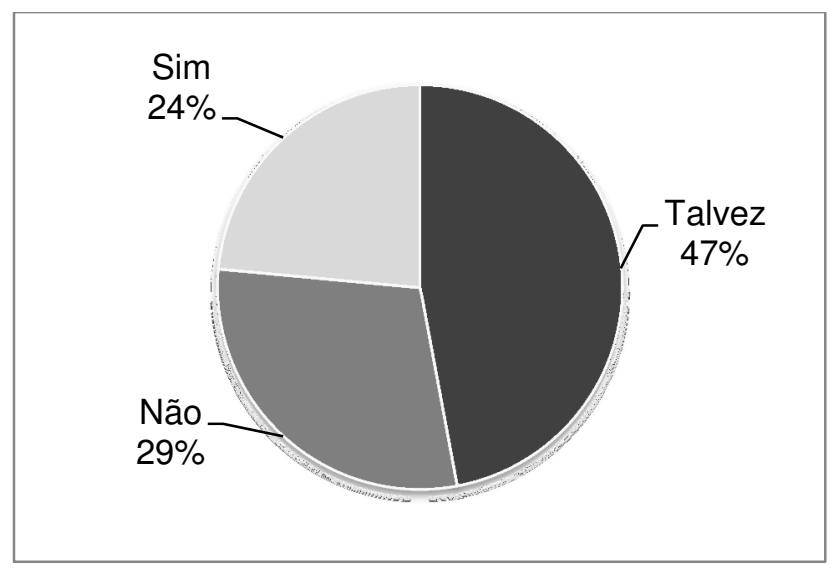

Figura 5: Interesse dos professores em realizar especialização sobre o tema.

Ao realizar tal questionamento, averiguou-se que seis (6) dos participantes da pesquisa nunca haviam atuado com alunos com deficiência. Assim, estes foram perguntados se apresentavam ou não interesse em fazer pós-graduação na área da Atividade Física Adaptada ou na área da Educação Especial. Para ilustrar os resultados, elucida-se a Figura 6.

Conexões: revista da Faculdade de Educação Física da UNICAMP, Campinas, v. 13, n. 1, p. 1-19, jan./mar. 2015. ISSN: 1983-9030 


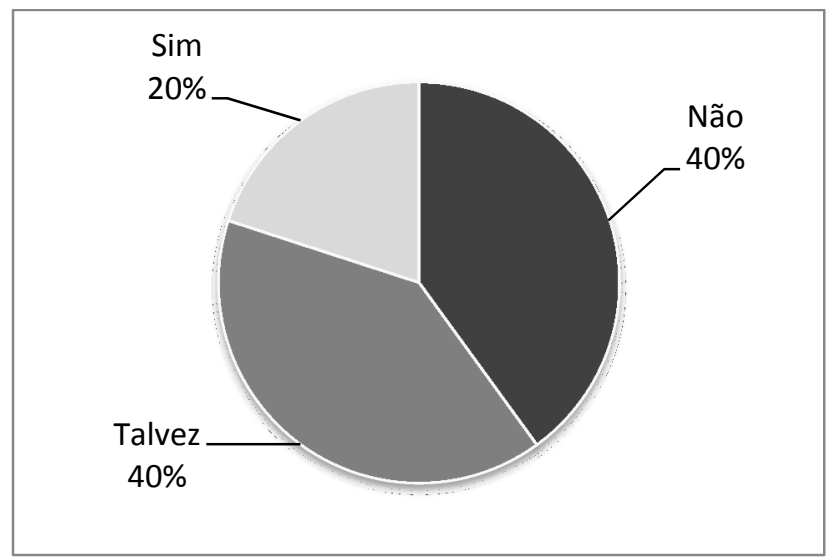

Figura 6: Atualização na área dos professores que nunca tiveram alunos com deficiência.

Ao analisar a Figura 6, nota-se que houve a mesmo percentual nas respostas "Não" (40\%) e "Talvez" (40\%) e somente $20 \%$ dos professores que nunca atuaram com alunos com deficiência demonstrou possuir interesse em fazer um curso de especialização na área.

A pesquisa de Filus e Martins Junior ${ }^{20}$ corrobora com que muitos dos entrevistados $(71,42 \%)$ afirmaram considerar essencial a realização de um curso de pós-graduação para se conhecer melhor a população e para realizar um trabalho com sucesso.

Percebe-se então que os professores reconhecem a importância que a atualização traz para essa área. Neste interim, destaca-se que apenas seis (6) dos 30 professores nunca tiveram alunos com deficiência, o que reflete a ampla presença desta população no ambiente escolar, porém, mesmo estes, em sua maioria, demonstram interesse em realizar uma especialização.

Observa-se que, na prática, ainda são poucos os professores participantes do estudo que possuem especialização. Este fato pode ser justificado pelo desinteresse dos professores em atuar com alunos com deficiência ou também pela falta de tempo dos participantes em relação a fazer esta especialização. 


\section{CONSIDERAÇÕES FINAIS}

Partindo do objetivo geral pontuado para o presente estudo, percebe-se que ainda existem muitas lacunas no que tange os processos de qualificação e aperfeiçoamento para o trabalho junto a pessoas com deficiência no ambiente escolar.

Por meio dos resultados apresentados, verifica-se que os professores evidenciam que não estão aptos para atuar com alunos com deficiência e apontam, principalmente, a falta de atualização nesta área como elemento de maior dificuldade para que práticas pedagógicas inclusivas sejam aplicadas, a fim de garantir o desenvolvimento desta população inclusa no ambiente escolar.

Desta forma, conclui-se ainda que a falta de especialização é significativa, pois a maioria dos professores aponta que não possui cursos ou especializações na área, visto que os participantes da pesquisa apontaram possuir dificuldades em suas intervenções docentes no que tange o processo de ensino e aprendizagem dos educandos, em virtude de características e peculiaridades próprias oriundas de suas deficiências.

Entende-se então que a atuação voltada para alunos com deficiência deve ser tratada com mais ênfase no cotidiano dos profissionais da área, pois todo e qualquer aluno deve ser tratado de forma igualitária, principalmente nas aulas de Educação Física, onde a diversidade humana é evidenciada de maneira mais ampla.

Sugere-se então a realização de pesquisas que envolvam a temática da Inclusão de pessoas com deficiência no ambiente escolar, voltadas principalmente a práticas pedagógicas que promovam a inclusão e participação igualitária de todos os alunos, visando subsidiar intervenções docentes. Ainda ressalta-se a importância do fornecimento de cursos práticos e teóricos envolvendo tal temática.

\section{REFERÊNCIAS}

${ }^{1}$ MENDES, E. G. Deficiência mental: a construção científica de um conceito e a realidade educacional, 1995. 387f. Tese (Doutorado em Psicologia) - Instituto de Psicologia, Universidade de São Paulo, São Paulo, 1995.

Conexões: revista da Faculdade de Educação Física da UNICAMP, Campinas, v. 13, n. 1, p. 1-19, jan./mar. 2015. ISSN: $1983-9030$ 
${ }^{2}$ MONTEIRO, A. P. H. Há mudanças nas concepções do professor do ensino fundamental em relação à inclusão após a inserção de alunos deficientes? 2006. 140f. Dissertação (Mestrado em Educação) - Faculdade de Filosofia e Ciências, Universidade Estadual Paulista, Marília, 2006.

${ }^{3}$ MEDINA, J. P. S. A Educação física cuida do corpo e "mente". São Paulo: Papirus, 1983.

${ }^{4}$ COSTA,V. L. Prática da Educação Física no $1^{\mathbf{0}}$ grau: modelo de reprodução ou perspectiva de transformação? São Paulo: Ibrasa, 1984.

${ }^{5}$ CARMO, A. A. Educação Física: crítica de uma formação acrítica: um estudo das capacidades e habilidades intelectuais solicitadas na formação do profissional de Educação Física. Dissertação de mestrado: Universidade Federal de São Carlos, 1982.

${ }^{6}$ MOREIRA, W. W. Educação Física: uma abordagem fenomenológica. Campinas: Ed. da Unicamp, 1991.

${ }^{7}$ DAÓLIO, J. A representação do trabalho do professor de Educação Física na escola: do corpo matéria-prima ao corpo cidadão. Revista Brasileira de Ciências do Esporte, Campinas, p.181186, 1993.

${ }^{8}$ DARIDO, S. C. Teoria, prática e reflexão na formação profissional em Educação Física. Motriz, Rio Claro, v. 1, n. 2, 1995.

${ }^{9}$ MARQUES, U. M.; CASTRO, J. A. M.; SILVA, M. A. Actividade física adaptada: uma visão crítica. Revista Portuguesa de Ciências do Desporto, v. 1, n.1, 2001.

${ }^{10}$ BRASIL. Congresso Nacional. Lei $n^{\mathbf{0}}$ 12.796, de 4 de abril de 2013, que estabelece a alteração das Diretrizes e Bases da Educação Nacional. Disponível em: http://www.planalto.gov.br/ccivil 03/ ato2011-2014/2013/lei/112796.htm.

${ }^{11}$ CIDADE, R. E. A; FREITAS, P. S. Noções sobre Educação Física e desportos para portadores de deficiências: uma abordagem para professores de $1^{\circ}$ e $2^{\circ}$ grau. Uberlândia: INDESP, 1997. 
${ }^{12}$ PALlA, A. C.; CASTRO, E. M. Atitude de professores e estudantes de educação física em relação ao ensino de alunos com deficiência em ambientes inclusivos. Revista da Sobama, v. 9, n. 1, p. 25-34, 2004.

${ }^{13}$ MAZZOTTA, M. J. S. Fundamentos de educação especial. São Paulo: Pioneira, 1997.

${ }^{14}$ BORELLA, D. R. Atividade física adaptada no contexto das matrizes curriculares dos cursos de Educação Física. 2010. 166f. Tese (Doutorado em Educação Especial) Centro de Educação e Ciências Humanas, Universidade Federal de São Carlos, São Carlos, 2010.

${ }^{15}$ CRUZ, M. S. et al. Prevalência de deficiência auditiva referida e causas atribuídas: um estudo de base populacional. Cadernos de Saúde Pública, Rio de Janeiro, v. 25, n. 5, p. 1123-1131, maio 2009.

${ }^{16}$ SILVA, R. F.; SEABRA JÚNIOR, L.; ARAÚJO, P. F. Educação Física adaptada no Brasil: da história a inclusão. São Paulo: Phorte, 2008.

${ }^{17}$ THOMAS, J. R.; NELSON, J. K.; SILVERMAN, S. J. Métodos de pesquisa em atividade física. 6. ed. Porto Alegre: Artmed, 2012.

${ }^{18}$ BRASIL. Ministério da Educação e Cultura. Conselho Federal de Educação. Resolução no 03/87, 1987. Disponível: http://www.ufpb.br/sods/consepe/resolu/1990/Res0387-cfe.htm

${ }^{19}$ SOUZA NETO, S. et al. A formação do profissional de Educação Física no Brasil: uma história sob a perspectiva da legislação federal no século XX. Revista Brasileira Ciências do Esporte, v. 25, n. 2, 2004.

${ }^{20}$ FILUS, J.; MARTINS JUNIOR, J. Reflexões sobre a formação em Educação Física e a sua aplicação no trabalho junto as pessoas com deficiência. Revista da Educação Física/UEM, Maringá, v. 15, n. 2, p. 79-85, 2004.

${ }^{21}$ MACIEL, M. R. C. Portadores de deficiência: a questão da inclusão social. São Paulo em Perspectiva, São Paulo, v. 14, n. 2, p. 51-56, 2000.

Conexões: revista da Faculdade de Educação Física da UNICAMP, Campinas, v. 13, n. 1, p. 1-19, jan./mar. 2015. ISSN: 1983-9030 
${ }^{22}$ SANT'ANA, I. M. Educação inclusiva: concepções de professores e diretores. Psicologia em Estudo, Maringá, p. 227-234, maio/ago. 2005.

Recebido em: 28 mar. 2014

Aceito em: 25 nov. 2014

Contato: robson_frank_91@hotmail.com 